\title{
List of tables and boxes
}

\section{Tables}

5.1 Public's agenda for President and Congress 2001-2011

263

7.1 RTAs notified to the WTO by type as of March 2007

9.1 A Proposal for a Two-Speed Protocol on Climate Change with a Dual Timetable

\section{Boxes}

7.1 Examples of cooperation in one area of special interest to the parties 